Capítulo 9

\title{
A reconfiguração da sociedade na era da desinformação: reflexões a partir da vertente crítica de Armand e Michèle Mattelart
}

DOI: https://doi.org/10.16921/ciespal.23.29

Larissa Conceição dos Santos

Marco Bonito

Unipampa/Brasil

Rafael Foletto

UFSM/Brasil

\section{Resumo}

O capítulo visa refletir sobre a problemática da (des)informação na atualidade a partir da perspectiva crítica da comunicação, de Armand e Michèle Mattelart. De maneira específica, busca-se analisar as transformações da sociedade, neste início do século XXI, a partir do lugar central ocupado pela informação. Para este fim, realiza-se uma investigação teórica e reflexiva, com base em pesquisa bibliográfica e documental, cuja abordagem comunicacional é de natureza crítica. Como contribuições, problematiza-se o fenômeno da desordem informacional vigente, apontando as possibilidades e limitações na reconfiguração da sociedade da informação para a sociedade desinformada.

Palavras-chave: Comunicação, informação, sociedade, perspectiva crítica, Mattelart. 


\begin{abstract}
The chapter aims to reflect on the problem of (dis)information nowadays from the critical perspective of communication, by Armand and Michèle Mattelart. In a specific way, we seek to analyze the transformations of society, at the beginning of the 21st century, from the central place occupied by information. To this end, a theoretical and reflexive investigation is carried out, based on bibliographic and documentary research, whose communicational approach is of a critical nature. As contributions, the phenomenon of current informational disorder is problematized, pointing out the possibilities and limitations in the reconfiguration of the information society for the uninformed society.
\end{abstract}

Keywords: Communication, information, society, critical perspective, Mattelart.

\title{
Introdução
}

Quando, em 2001, nos primórdios do século XXI, Armand Mattelart publicou o seu livro "História da Sociedade da Informação" o conceito de desinformação tinha percepção distinta do que nas duas décadas depois. Este um momento sociopolítico e midiático que se configurou a partir de mediações, lógicas capitalistas hegemônicas e algumas raras alternativas contra-hegemônicas, entendidas aqui como antagônicas ao sistema vigente. Dessa forma, a sociedade deste início de século XXI, ao final da segunda década, apresenta-se como herdeira dos valores da suposta "sociedade do conhecimento". Contudo, atua de tal maneira que se é possível desconfiar do bom uso e apropriação dessa herança.

Essa percepção empírica nos provoca a indagar como, por que e de que maneira se reconfigurou a sociedade da informação, neste início do século, e se podemos considerá-la, então, como: a sociedade da 
desinformação? Propomo-nos aqui a responder tais questionamentos a partir de um estudo teórico (Maldonado, 2011) - apoiado em pesquisa bibliográfica e documental - mas também reflexivo, a partir do plano empírico, em que se problematiza o fenômeno da desinformação na atualidade sob a ótica da perspectiva crítica da comunicação inaugurada por Armand e Michèle Mattelart.

A princípio, destacamos que Mattelart (2002) procurou chamar a atenção e registrar historicamente, de maneira crítica e reflexiva, as mediações tecno-informacionais que configuraram a história da Sociedade da Informação no século XX. Apontou para a gênese do problema ao alertar que o positivismo científico associado ao desenvolvimento das lógicas do capital promoveria uma sociedade funcionalista que estaria disposta a adotar práticas prefiguradas ante a emergência da sociedade em rede. A matéria prima essencial para todas essas transformações, ao longo desse tempo, foi a informação. Mas afinal, o que é informação, dado que esta palavra ganhou tantos significados ao longo do tempo e perdeu sentidos pelo caminho?

Considera-se a informação como o conceito-chave responsável pela mudança paradigmática dos rumos das diversas sociedades do século passado, que mesmo em seus tempos sociais distintos e geolocalizações distantes entre si, foram e ainda são implicadas por lógicas globalizadas, capitalistas e neoliberais. Estes efeitos são sentidos e ecoam na reconfiguração da sociedade neste início do século XXI. Na retrospectiva realizada por Mattelart (2002) encontramos as perspectivas dessas configurações da sociedade da informação, assim, reconhece-se que o conceito de informação contido na Teoria Matemática da Comunicação, de Claude Shannon (1949), é fundador dessa cisma social, principalmente em função de sua episteme positivista que se tornaria, ao longo do tempo, um paradoxo social. Como é sabido, a definição de informação encontrada na dissertação de Shannon era estritamente quantitativa (físico-estatística) e conforme exposto por Mattelart “[...] Trata-se sobretudo de 'quantidade de informação'. Ela não leva em conta a raiz etimológica da informação, que denota um processo que dá 
forma ao saber graças à estruturação de fragmentos do saber" (MacKay, 1969; Dubos, 1970 apud Mattelart, 2002, p. 63).

Essa visão funcionalista colaborou, naquele momento, para o desenvolvimento da chamada "Era da informática", ou melhor: a era da informação automatizada, mecânica e controlada. A era computacional estava inaugurada, mas faz-se necessário lembrar que um "computador", na essência primária, é uma máquina de contabilizar dados. Porém, com o tempo, a potência midiática dessas máquinas de computar se revelou como sendo uma formidável estrutura, arquitetada para produzir efeitos e sentidos, por meio de processos comunicacionais, discursos e narrativas cada vez mais estratégicas, homogêneas e representantes do modelo mental hegemônico, uma mídia essencialmente.

O "pai da cibernética", Norbert Wiener, era para Mattelart (2002, p.56), uma voz dissonante à época, ou como ele preferiu chamar "uma promessa humanista na contracorrente”. Na concepção da cibernética proposta por Wiener, a descentralização e o descontrole das informações eram a chave-mestra para uma segunda revolução industrial, onde cada cidadão seria beneficiado por mais liberdade. Mas, seu ceticismo o leva à ressalva: as máquinas de comunicação, para servirem ao projeto humanista, precisariam ser capazes de contrariar a entropia, com a livre circulação das informações sem entraves. No entanto, a história das sociedades revela que o "quarto poder": a imprensa (mídia) é submissa ao "quinto poder": o mercado (economia política) e esta característica viria a corromper o caráter da cibernética. A preocupação de Wiener (1948, p.168 apud Mattelart, 2002, p.57), sobre a nociva mercantilização das fontes de informação, se consolida, ao observar que existem sempre "[...] estatísticos, sociólogos e economistas disponíveis para vender seus serviços a essas empresas. Felizmente para nós, esses mercadores de mentiras, esses exploradores da credulidade, ainda não chegaram a um grau tal de perfeição que faça com que todas as coisas funcionem como queiram". Porém, a prometida "sociedade do conhecimento" não passou de um vislumbre cibernético utópico. $\mathrm{Na}$ prática, as elites econômicas e seus entes institucionais ocuparam os 
ciberespaços midiáticos e desenvolveram as lógicas que vigoram e domesticam a cibercultura que conhecemos neste início de século XXI.

A partir dessa premissa, considera-se que a percepção do historiador Fernand Braudel sobre a forma do modelo informacional que estava proposto, em meados do século passado, realiza-se tardiamente e, mais evidentemente, neste início de século XXI. À época, ele proferiu um aforismo que pode ser entendido como uma profecia apocalíptica do mal uso da arquitetura das informações e dos sistemas, ao enfatizar que uma estrutura, na visão dos historiadores, é entendida como um conjunto (uma arquitetura), porém "[...] é mais ainda uma realidade que o tempo usa mal e veicula demoradamente. Certas estruturas, por viverem muito tempo, tornam-se elementos estáveis de uma infinidade de gerações: embaraçam a história, incomodam-na, e assim comandam seu fluxo" (Braudel, 1965, p. 268).

Quando Braudel afirmou que estas são "uma realidade que o tempo usa mal e veicula demoradamente", provavelmente, ele não imaginou que o efeito desse mal uso fosse tamanho que transformaria a sociedade da informação numa sociedade desinformada ao longo do tempo. Em 2020, os discursos negacionistas e contrários à racionalidade científica, bem como, aqueles que geraram odes às desinformações, dominam as narrativas nas redes sociais digitais, onde os discursos políticos têm reconfigurado e corroído profundamente o caráter da sociedade que "vive" em rede mediada por dispositivos midiáticos.

Para Marco Antônio de Almeida (2009), o conceito de informação não tem um consenso estabelecido, porém, entre as vertentes de pensamento que surgem nos anos 1970 dedicadas ao entendimento do que se trata "informação", parece-lhe mais interessante a perspectiva estabelecida por Armand Mattelart. Nessa ótica, a informação é uma matéria-prima beneficiada como um "dado", que se torna um recurso essencial para as trocas que ocorrem no âmbito social da economia. Para ele "o fato é que a informação em suas múltiplas formas e concepções (científica, artística, mercadológica) tornou-se central na dinâmica social contemporânea" (Almeida, 2009, p.13), fator que evidencia a diferença 
com relação à concepção cibernética - que considera a informação como um processo cuja finalidade é a manutenção do sistema ao qual pertença. Por outro lado, quando ela é sintetizada como um dado, "torna-se passível de ser entendida como objeto, passível de apropriação e mercantilização" (idem).

Na perspectiva crítica de Armand e de Michèle Mattelart, a informação não é analisada como objeto conceitual, mas sim, de maneira mais ampla "é compreendida articulada aos contextos políticos e econômicos nos quais é produzida e nos quais circula, constituindo-se tanto como elemento de dominação quanto como o elemento capaz de impulsionar o processo revolucionário" (Araújo, 2009, p.113). É neste sentido, que a problematização apresentada até aqui deve provocar reflexões sobre as possibilidades de um processo revolucionário informacional, ou melhor, num conceito atualizado: comunicacional, a partir da cibercultura estabelecida neste início de século, desse modo, historicamente configurada sob ilusões de supostas liberdades, inalcançáveis como um ponto utópico no horizonte.

\section{Os estudos de Armand e Michèle Mattelart sobre a sociedade da informação: contributos teórico-conceituais}

Ao longo dos últimos 200 anos, a humanidade passou por grandes revoluções tecnológicas, a exemplo da invenção da comunicação, que ofereceu as bases, as estruturas dos sistemas midiáticos, que no século XX adquiriram um caráter de penetração social, transformando, inclusive, a própria economia capitalista mundial, tornando possível a construção de campos de pesquisas formais, com autonomia relativa, nos quais o modelo liberal-representativo se tornou o modelo adequado para esses.

No âmbito da América Latina, Fuentes Navarro e Lopes (2001) apontam para a escassa reflexão existente a respeito da institucionalização dos estudos de Comunicação na região. Nesse marco, também 
assinalam o pouco interesse concedido aos mecanismos e processos institucionais que intervêm no desenvolvimento das investigações, que poderíamos chamar de comunicativas ou comunicacionais. Entretanto, no caso da região latino-americana, é impreterível observar como ocorreu uma forte ebulição intelectual, referente às problemáticas comunicacionais, a partir dos anos 1960. Nesse período, em vários pontos e centros da América Latina, foi produzida investigação avançada, pesquisa séria, argumentos inovadores, críticos e reformuladores das práticas e dos pensamentos.

Nesse sentido, na América Latina, no final da década de 1950, surgiram importantes projetos descritivos e interpretativos sobre as estruturas comunicacionais, como o Centro Internacional de Estudios Superiores de Comunicación para América Latina (CIESPAL), no Equador; o Centro de Estudos da Realidade Nacional do Chile (CEREN), no Chile; e, o Instituto Latino-americano de Estudos Transnacionais (ILET), no México. Embora, no começo, não assumissem um trabalho de pesquisa permanente, os conhecimentos desenvolvidos nesses espaços reverberam na comunidade acadêmica (Berger \& Schwaab, 2014). Dessa forma, os centros de pesquisa se dedicam a repensar políticas de comunicação e o papel dos meios massivos na formação da consciência política dos cidadãos. Enfim, tratava-se de um movimento de construção de alternativas comunicacionais, ou seja, de busca pela construção de políticas democráticas de gestão dos meios massivos.

Esses estudos tinham por base a genealogia do pensamento, a contextualização como aspecto decisivo da problemática, a necessidade de formulação de uma estrutura de contextos múltiplos e uma visão abrangente e particular, procurando trabalhar com o olhar do controle nas tecnologias e do terrorismo como catalizador da cultura do medo, como o modelo de gestão. Assim, no seu começo, o pensamento comunicacional latino-americano foi bastante motivado pelo contexto político da região - à época, dominado por regimes ditatoriais.

Para Mattelart e Mattelart (2004), então, torna-se imprescindível pensar os processos comunicacionais como parte do sistema capitalista 
mundial, evidenciando a necessidade da pesquisa empírica ao longo do percurso científico desse campo.

O esquema de pensamento mecânico e linear se vê deslegitimado pelo pensamento organicista (os paradigmas propostos pelas ciências da vida tornaram-se, como vimos, referências incontornáveis). Ao método objetivo, será oposta a primazia dos valores; às técnicas quantitativas, técnicas empíricas qualitativas; à atitude lógica, a atitude heurística; ao cognitivo, o intuitivo; à projeção linear, a multiplicidade das escolhas e das opções (Mattelart \& Mattelart, 2005, p. 83).

Assim sendo, é fundamental pensar processos enquanto construções históricas, assumindo o poder como instância importante na configuração dos processos comunicacionais. Visando uma abordagem político-econômica da comunicação, sobretudo nas sociedades da América Latina e no sentido de compreender criticamente as estratégias imperialistas de domínio dos sistemas comunicacionais no espaço da região, Armand e Michèle Mattelart (1989) oferecem importantes parâmetros para pensar, refletir e problematizar o campo da Comunicação como escopo estratégico para a política. Para eles, os pesquisadores tinham como principal desafio compreender as estratégias e as estruturas que compõem os processos de comunicação que perpassam as sociedades nas quais centram as suas análises. Trata-se, assim, de buscar o entendimento das estratégias adotadas pelos meios hegemônicos de comunicação para construir as realidades que retratam.

Ainda, no que concerne às sociedades atuais da América Latina, observa-se que os meios de comunicação de massa surgem como protagonistas, trazendo desafios de outras dimensões, propondo novas ações, molduras e sujeitos, bem como, construindo concepções distintas acerca do que seria o social, a política e a democracia.

Compreende-se o campo da comunicação como ponto estratégico para a política (Mattelart \& Mattelart, 1989), observando-a enquanto um espaço fundamental para o fortalecimento da democracia, da cidadania e da integração regional. Atualmente, a comunicação atingiu 
significativos níveis de avanços tecnológicos, penetração social, organização sistêmica e poder simbólico (Mattelart, 2008). Assimilando toda complexidade que se estabelece nas configurações da pesquisa, é possível tanto uma visão abrangente dos mundos nos quais acontecem os processos, quanto um olhar particular, a partir da comunicação e do que se está analisando.

Nesse sentido, Armand e Michèle Mattelart (1989) buscam construir uma nova definição da noção de sujeitos, ancorados em uma ótica centrada na política e na cultura popular. Assim, esse processo de construção da visão dos indivíduos necessitaria surgir de um entendimento aprofundado dos grupos sociais e das comunidades que constituem a sociedade a qual o pesquisador lança a sua análise. Para eles, as experiências pessoais se constituem em experiências sociais.

Assim, a dimensão dos sujeitos é entendida como perspectiva teórica integradora do processo comunicacional e como momento privilegiado da produção de sentido. Dessa maneira, "o mundo da produção de sentidos, nas distintas culturas, é múltiplo, complexo e não configura estruturações de significação mecânicas e deterministas" (Maldonado, 2014, p. 18). Porém, Mattelart e Neveu (2004) enfatizam que também é necessário atentar para a questão da produção. Mais uma vez, a ideia é ter uma observação interdisciplinar ampla da realidade que, derivando da abordagem trazida pelos autores, pode ser compreendida como um processo social em fluxo. Entende-se que as processualidades do fazer científico, no Campo da Comunicação, devem buscar construções teórico-metodológicas e epistemológicas que sustentem uma visão global e complexa do processo comunicativo, para além das dimensões dos efeitos e conteúdos (Kaplún, 2002). Ou seja, a trilha dos processos informacionais em toda a sua extensão e inter-relação, compreendendo a produção de sentidos de forma ampla, tanto na construção dos textos/ discursos, quanto nas leituras e vivências dos sujeitos.

Compreende-se que o debate acerca da sociedade da informação e dos marcos conceituais e das tipologias, está ligado a um entendimento da contemporaneidade, da fase atual do modo de produção capitalista 
(em especial em sua versão midiática) e dos seus desdobramentos de caráter ético, cultural, tecnológico, econômico e histórico, que se apresentam na sociedade atual. Esse debate sobre os fluxos de comunicação e informação ganhou amplo debate mundial, culminando no Relatório McBride, editado pela Unesco, nos anos 1970, o qual observou trocas desiguais tanto no âmbito técnico, quanto nos âmbitos econômico e social, respaldando o entendimento da comunicação como um direito, como um espaço que deve ser plural, democrático e participativo.

\section{A Informação na Atualidade: Dis-information, Mis- information ou Mal-information?}

Quase quatro décadas após à publicação do relatório McBride (1980) pela Unesco - Voix multiplex, un seul monde - que, por um lado, expunha as desigualdades no fluxo info-comunicacional entre os países e, por outro, propunha uma "nova ordem mundial da informação e da comunicação" Nações Unidas, intitulada Journalism, fake news and disinformation ${ }^{2}$ reafirma o papel central da informação na sociedade contemporânea, e revela, no entanto, que o intento de dominação tecno-informacional imperialista (Mattelart \& Mattelart, 1999; Mattelart, 2002), travestido de projeto de integração mundial, assume hoje novas proporções.

O discurso da comunicação sem barreiras, da democratização do acesso à informação, propaga-se atualmente suscitado pelas

1 Em reflexão tecida à época e sobre o desenvolvimento e publicação do relatório McBride da Unesco, Armand e Michèle Mattelart (1999, p.121) afirmaram que: "Apesar desses limites, tais debates e os estudos por eles suscitados lançaram um grito de alarme sobre a troca desigual dos fluxos de imagens e informações. Nessa ocasião, fizeram-se ouvir as vozes dessa parte majoritária do mundo cuja realidade é muitas vezes conhecida por meio dos filtros dos estudos realizados pelos peritos dos grandes países industriais. Dominantes nos hemiciclos internacionais, as referências da sociologia da modernização de origem americana foram, no decorrer da década de 70, substituídas pelas representações de desenvolvimento formuladas por aqueles que se faziam sujeitos do próprio desenvolvimento".

2 A publicação da Unesco (2019) sobre Jornalismo, Fake News e Desinformação é apresentada como um manual para educação e treinamento em jornalismo, da série "UNESCO sobre Educação em jornalismo", organizada em sete módulos e direcionada a profissionais e acadêmicos da área. 
tecnologias que decorrem do surgimento da internet e da rede mundial de computadores. Porém, suas implicações problemáticas podem ser percebidas agora não pela falta, escassez ou acesso desigual às informações, mas pelo excesso destas e pela dimensão perigosa que assumiram, como expressões de poder e de controle ideológico, ao subverterem a tecnologia ao serviço da manipulação e distorção da verdade.

Nessa perspectiva, o excesso de informação está colocando a sociedade em risco: a disputa pelo controle informacional torna-se uma guerra - simbólica e ideológica - central na atualidade, cujo armamento mais perigoso e ameaçante às democracias pode ser observado através das estratégias de desinformação e as variantes que emergem a partir dela. Dentre os sujeitos mais afetados, e potencialmente alvo dessas práticas desinformativas, Berger (2019, p.8) destaca as populações que não possuem condições de acesso a informações de qualidade, obtidas por meio de notícias verificáveis e de condutas jornalísticas confiáveis, revelando um perigo específico, pois “[...]fake news nesse sentido são normalmente gratuitas - ou seja, pessoas que não podem pagar por jornalismo de qualidade ou que não têm acesso a meios de comunicação independentes, são especialmente vulneráveis à desinformação e informação incorreta".

Para Ireton e Posetti (2019) a desinformação e as fake news são histórias antigas agora fomentadas por tecnologias novas. Isso significa que a propagação de informações e notícias falsas ou falaciosas sempre existiram, sob outras formas (fofoca, calúnia, difamação verbal, etc.) e impulsionadas através dos mais variados formatos (sejam eles midiáticos ou informais, como o famoso boca-a-boca). Porém, o que observa-se na atualidade é a amplificação dessas práticas, graças a visibilização proporcionada na internet e, especialmente, através das redes sociais digitais (Wardle \& Derakhshan, 2017). Além disso, as tecnologias digitais também possibilitam e facilitam a manipulação (e mesmo a fabricação) de mensagens e conteúdos (Ireton \& Posetti, 2019), por meio de softwares e mecanismos de compartilhamento de informações que empoderam sujeitos comuns, antes apenas públicos consumidores, ao lugar de produtores e propagadores de conteúdos. 
A expansão acelerada de informações, notícias e fatos falsos ou mentirosos é também observada por Igor Sacramento e Raquel Paiva como uma fenômeno que precisa ser analisado em sua dimensão política (governamental) mas também técnica (funcionamento social da rede eletrônica), especialmente diante de um público-usuário cada vez mais jovem e com pouco discernimento - entre o discurso informativo e o mercadológico - face ao conjunto complexo e diverso de informações disponíveis na sociedade, de maneira que "o jogo atual do mercado e da rede perfaz-se pela amplificação tecnológica - a eletrônica e a semiose redefinem e alargam o espaço - do ponto de vista. Este, em vez de apenas martelado, é irradiado como uma contaminação atômica ou viral, propagando-se por contágio ou por ondas de impacto sensível" (Sacramento \& Paiva, 2020, p.84).

Tal panorama configura e determina o estado atual da "sociedade da desinformação", cujas características foram analisadas e apresentadas no relatório ${ }^{3}$ do European Council (2017) a partir do fenômeno denominado por Claire Wardle e Hossein Derakhshan de "desordem informacional", compreendido pelo estado de poluição informacional no qual a sociedade estaria submetida.

Embora o impacto histórico dos rumores e do conteúdo fabricado tenha sido bem documentado, argumentamos que a tecnologia social contemporânea revela que estamos testemunhando algo novo: a poluição da informação em escala global; uma complexa rede de motivações para criar, disseminar e consumir essas mensagens 'poluídas'; uma miríade de tipos de conteúdo e técnicas para amplificar conteúdo; inúmeras plataformas hospedando e reproduzindo este conteúdo; e velocidades de comunicação vertiginosas entre pares confiáveis (Wardle \& Derakhshan 2017, p.4, em livre tradução).

3 O relatório, encomendado pelo Conselho Europeu e publicado em 2017 sob o título Information Disorder: Toward an interdisciplinary framework for research and policymaking (Desordem informacional: Rumo a uma estrutura interdisciplinar de pesquisa e formulação de políticas, em livre tradução), apresenta-se como "uma tentativa de examinar de forma abrangente a desordem informacional e seus desafios relacionados", entre eles os impactos e a influência da poluição informacional no contexto eleitoral e das democracias. 
Nesse contexto, Wardle e Derakhshan (2017; 2019) identificam as dinâmicas e apropriações informacionais e os perigos decorrentes da criação, disseminação e consumo de informações falsas, sejam estas práticas intencionais ou não. Destacam que, embora uma informação seja considerada verdadeira, pode ser manipulada ou empregada de maneira a prejudicar outrem. A partir dessas observações iniciais, propõem analisar o fenômeno da desordem informacional contemporânea por meio do conceitos de mis-information, dis-information e mal-information (Wardle \& Derakhshan 2017; 2019), conforme demonstrado na Figura 1.

\section{Figura 1}

Desordem informacional

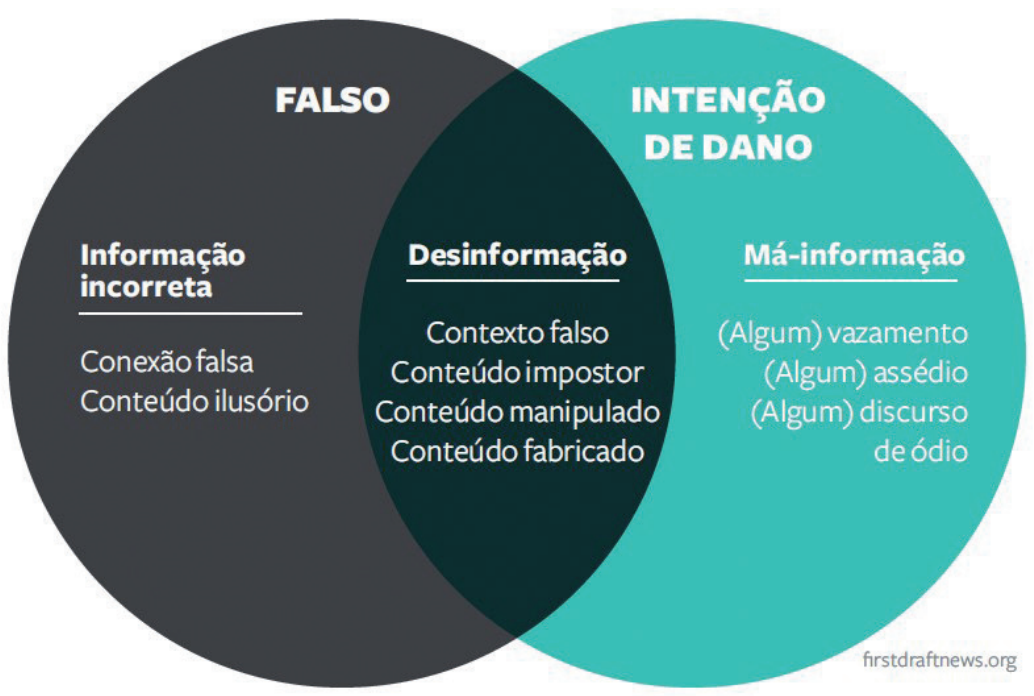

Nota: Reproduzido a partir de Jornalismo, Fake news e desinformação (p.48) por C.Wardle \& H.Derakhshan, 2019, Unesco. Copyright 2019, Unesco. 
Na perspectiva dos autores, apresentada primeiramente no relatório do Conselho Europeu (2017) e retomada novamente na publicação especial da Unesco (2019) sobre jornalismo e desinformação, erros e enganos não intencionais são abordados como mis-information, isto é, as chamadas "informações incorretas" que, embora não tenham em sua origem o intuito de prejudicar alguém, podem resultar em dano decorrente da divulgação ou uso indevido (por terceiros) dessa informação equivocada.

Já a propagação intencional de uma informação, deliberadamente, sabendo tratar-se de algo falso é denominada por dis-information, ou desinformação, em português. Nesse caso, tem-se consciência do dano ou prejuízo causado pela disseminação de informação falsa, e a intenção por trás desse ato é, muitas vezes, o prejuízo gerado a outrem, enquadrando-se nestas as chamadas fake news.Trata-se, portanto, "de mentira intencional e deliberada, e resulta em usuários sendo ativamente desinformados por pessoas maliciosas" (Wardle \& Derakhshan, 2019, p.48).

Uma terceira categoria é proposta por Wardle \& Derakhshan (2017) para designar a má-informação ou mal-information, que diz respeito às informações verdadeiras, porém disseminadas com a intenção de provocar prejuízo a alguém (Figueira \& Santos, 2019). Ressalta-se, nesse caso, a importância de distinguir entre mensagens verdadeiras e falsas, mas, sobretudo reconhecer o uso indevido de informações reais (ou com uma parcela de verdade) produzidas, reproduzidas e compartilhadas por indivíduos que buscam lesar, em lugar de servir ao interesse público (Wardle \& Derakhshan, 2019, p.48)

Os apontamentos acima lançam luz sobre uma realidade problemática, que decorre da desordem da informação e afeta, influencia e coloca em risco as democracias atuais. A criação, produção e distribuição de informações falsas ou a manipulação e distorção de verdades contribui ao esvaziamento dos sentidos informativos, à banalização do jornalismo fundamentado e, consequentemente, à involução social operada a partir do controle tecno-político da informação. 
De uma sociedade da informação (Mattelart, 2002), aparelhada pelas redes e conexões globais como tecno-utopia capitalista, passamos à uma sociedade desinformada. Porém, a guerra agora não é pelo controle tecno-informacional, mas sim, utiliza a tecnologia como palco e veículo para uma disputa informacional cujo belicismo reside na disseminação de mensagens falsas (ou manipulação de verdades), capazes de alterar o curso e o controle político de nações (Faris et al. 2017; Ferrara 2017; Canavilhas et al. 2019), gerar o enfraquecimento das democracias globais (Bennett \& Livingston, 2018) e, ainda, podendo provocar a 'morte por desinformação', como no caso das campanhas anti-vacinas (Fernandes \& Montuori, 2020) e de orientação e controle de epidemias (Henriques, 2018; Sousa et al. 2020).

\section{A reconfiguração da sociedade da desinformação}

Segundo relatou Mattelart (2002), no encontro da Cúpula Econômica e Social Europeia, realizada no ano 2000 em Lisboa, foi proposto um objetivo estratégico: "tornar a economia do conhecimento mais competitiva e mais dinâmica”. Para isso, os sistemas de educação deveriam ser estimulados e adaptar-se para formar mão de obra melhor e mais qualificada a partir das potencialidades da incipiente internet que, à época, dava seus primeiros passos como tecnicidade determinante da "sociedade em rede" em tempos de "informacionalismo", como bem definiu Castells (2006). Naquele tempo, a Europa vivia uma recente unificação comunitária, econômica e política, consagrada pela formação do bloco econômico da União Europeia que vigorava desde 1993. Contudo, as políticas educacionais eram de responsabilidade de cada país membro, mas, embora houvesse autonomia interna para decidir os rumos da educação, estes estavam submetidos às diretrizes econômicas da União Europeia, numa inter-relação que regula o próprio sistema de maneira autopoiética. A proposta visava gerar atores sociais aptos a atuar no cenário da "sociedade de mercado". 
Nessa perspectiva da economia liberal, os indivíduos passam a ser responsáveis pela sua empregabilidade ou o seu eventual desemprego, no tabuleiro do jogo da vida na "sociedade de mercado". Essa visão instrumentalista da educação faz parte do pragmatismo social-liberal que, como afirma Mattelart (2002, p. 135), fora induzido principalmente pelas ideias defendidas pelos Estados Unidos e corroboradas pelo eixo Londres-Madri. O que chama a atenção é que sob o pretexto de "estimular ativamente a aquisição de conhecimentos e competências para transformar a sociedade da informação emergente em uma sociedade do saber" (idem), os representantes políticos não estimularam o debate com a sociedade europeia, as decisões excluíram as possibilidades de consultas públicas, referendos ou plebiscitos. Este fato foi consagrado no relatório final produzido por um grupo externo de especialistas, que ainda ressaltavam críticas ao determinismo tecnológico.

A economia do saber reflete o caráter do informacionalismo como uma atualização do capitalismo, é a somatória dos conhecimentos individuais à insaciável fome do capital, em face da sociedade de mercado. O saber, então, havia se tornado a riqueza mais desejada neste início de século e a popularização do acesso à internet potencializou as informações para que se tornassem commodities digitais. Quanto mais informações acumuladas, mais sistemas de informação e dispositivos informáticos foram necessários para organizar e gerenciar o seu estoque e o fluxo/circulação. Enquanto isso, o sistema se retroalimentava fomentado por essa lógica oblíqua e pela chamada "mão invisível" do mercado.

Não obstante, não é de se estranhar que as empresas mais valiosas do mundo, na segunda década do século XXI, sejam justamente aquelas que atuam no setor das tecnologias da informação e da comunicação digital: Amazon: US\$221 bilhões (varejo); Google: US\$16o bilhões (tecnologia); Apple: US\$141 bilhões (tecnologia); Microsoft: US\$117 bilhões (tecnologia); Samsung: US\$94 bilhões (tecnologia) (Infomoney, 2020). Em março de 2020 o Comitê Gestor da Internet no Brasil publicou um 
relatório que é fruto da preocupação crescente em torno dos impactos causados pela infodemia de desinformações e notícias falsas que assolam as: "sociedade da informação"; "sociedade do conhecimento"; "sociedade do saber", principalmente após os fatos ocorridos no período pré-eleitoral das eleições presidenciais dos Estados Unidos. Bem como, no período que antecedeu o referendo do Brexit ${ }^{4}$ no Reino Unido, ambos em 2016, assim como no período pré-eleitoral da eleição para presidente no Brasil em 2018. Este relatório cita como fontes de inspiração a "Declaração sobre liberdade de expressão, fake news, desinformação e propaganda" (ONU, 2017), assinada pelo representante sobre Liberdade na Mídia da Organização para Segurança e Cooperação na Europa; pelo Relator Especial sobre Liberdade de Expressão da Organização dos Estados Americanos e pelo Relator Especial sobre Liberdade de Expressão e Acesso à Informação da Comissão Africana para os Direitos Humanos e das Pessoas. Além desse documento, também é citado um estudo encomendado pelo "Conselho da Europa" em 2017, que visava examinar os desafios comunicacionais na internet, bem como o uso massivo das tecnologias digitais. Sobre o intuito deste, o relatório do Comitê Gestor da Internet no Brasil ressalta:

O relatório produziu um modelo conceitual para apoiar formuladores de políticas, legisladores, empresas de tecnologia, profissionais da educação e organizações de mídia no enfrentamento de desafios relacionados à chamada "desordem informacional" (NIC.BR, [s.d.])

Percebe-se que o relatório brasileiro segue as mesmas orientações propostas e ainda acrescenta mais uma fonte: o Relatório do "Grupo de Alto Nível sobre notícias falsas e desinformação online” oriundo da Comissão Europeia em 2018. Este foi responsável por identificar uma mudança crucial no ecossistema midiático a partir do descrédito nas instituições tradicionais de informação como o jornalismo e a ciência,

4 Brexit: saída do Reino Unido da União Europeia. 
um ambiente propício para a infodemia das desinformações e notícias falsas. A solução encontrada pelo relatório baseia-se em cinco pilares:

I- proteger a diversidade e sustentabilidade do ecossistema midiático;

II- promover iniciativas de educação midiática;

III- garantir a transparência do ecossistema de notícias;

IV- promover pesquisa contínua sobre os impactos da desinformação para acompanhar a efetividade de medidas tomadas;

V- fortalecer usuários e jornalistas para se apropriarem de um ambiente tecnológico em rápido desenvolvimento. (NIC.BR, [s.d.])

O relatório brasileiro aponta para as realidades nacionais em função das características típicas do nosso ambiente sociopolítico e econômico. Nesse sentido, lembra que a democracia é jovem por aqui e está em desenvolvimento, assim como a desigualdade social e assimetria de poder são características determinantes nesse cenário. Além disso, há notório monopólio concentrado dos canais midiáticos o que inviabiliza a diversidade e a sustentabilidade do ecossistema comunicacional. Bem como a possibilidade de ter educação midiática nas escolas é uma espécie de luxo num país onde apenas $12 \%$ das pessoas são consideradas proficientes alfabetizadas e outras 30\% são consideradas completamente analfabetas funcionais. A diversidade midiática também é restrita, contém alta concentração de audiência, falta de transparência e sofre com interferências econômicas, políticas e religiosas. Nestas condições, a pontuação do país tem colocado o Brasil no que o relatório considera "situação sensível e situação difícil". (idem)

Soma-se a isso outras características sociais e ciberculturais brasileiras descobertas pela pesquisa TIC Domicílios 2019 do Centro Regional de Estudos para o Desenvolvimento da Sociedade da Informação $(2020)^{5}$, tais como: $74 \%$ da população é declaradamente usuária da rede (internet) e 99\% destas têm acesso pelo celular. O celular é o único meio

5 Pesquisa disponivel em: https://cetic.br/media/docs/publicacoes/2/20201123121817/tic_dom_2019_livro_eletronico.pdf 
de acesso para $58 \%$ da população brasileira e esta tem acesso, principalmente, por meio de planos de franquia de dados limitados. As operadoras de telefonia oferecem planos que dão acesso ilimitado, depois do consumo da franquia contratada, para aplicativos parceiros como o Facebook, Whatsapp e Twitter, o que faz com que esses aplicativos tenham também o monopólio dos discursos e narrativas.

Em função desse cenário, é notório que as medidas propostas pelos relatórios internacionais não vão surtir os efeitos desejados a curto prazo. A velocidade com a qual as organizações criminosas se articulam para promover notícias falsas e desinformação é muito maior do que a capacidade da sociedade civilizada tem para se organizar e combater essa infodemia. $O$ efeito colateral disso é que passam a vigorar, na sociedade, discursos que defendem o sistema regulatório, algo que fere a natureza da neutralidade da rede, mas que precisa ser debatido nos diversos setores da sociedade civil. Isto, inclusive, faz parte de uma das vertentes de propostas para solucionar o problema contidas no relatório, são elas: a) Sugestão de aperfeiçoamento do ambiente legal e regulatório; b) Construção de redes de combate à desinformação; c) Monitoramento, controle e prevenção; d) Pesquisa e formação. Como se pode constatar, nenhuma dessas propostas consegue, a curto prazo, resolver o problema, mas nem por isso, devem ser desconsideradas como colaboradoras a médio e longo prazo.

\section{Considerações Finais}

Nesta investigação, sob reflexão crítica, procurou-se compreender como, porque e que de maneira se reconfigurou a sociedade neste início do século e se podemos, então, considerá-la como a sociedade da desinformação? Sob pensamento crítico, buscou-se desenvolver, a partir de um estudo teórico, apoiado em pesquisa bibliográfica e documental, mas também reflexivo, problematizar o fenômeno da desinformação na atualidade sob a ótica da perspectiva crítica da comunicação inaugurada por Armand e Michèle Mattelart. 
Partiu-se de uma retrospectiva sobre a história da sociedade da informação, o próprio conceito de informação e pela inauguração da era da informática, para chegar à concepção da cibernética. Neste ponto, entende-se que a informação não é analisada como objeto conceitual, mas sim, de maneira mais ampla nos contextos políticos e econômicos, onde é produzida e circula, "constituindo-se tanto como elemento de dominação quanto como o elemento capaz de impulsionar o processo revolucionário" (Araújo, 2009, p.113).

Além disso, considera-se que os estudos e contribuições teórico-conceituais de Armand Mattelart sobre a sociedade da informação ajudam a desvendar os mistérios sobre as reconfigurações da atualidade social nestas duas décadas do século XXI. Principalmente no que tange o pensamento sobre os processos comunicacionais como parte do sistema capitalista mundial e em virtude das características e peculiaridades brasileiras. Sem esquecer que o campo da comunicação social é um setor estratégico para os interesses de qualquer sociedade que tenha um projeto de civilização que contemple e reconheça sua população como cidadãos e cidadãs de direitos humanos adquiridos. Nesse sentido, Armand e Michèle Mattelart buscam construir uma nova concepção para os sujeitos, relacionando-os com a política e cultura popular.

Ao definir as distinções entre os conceitos de desinformação, informação incorreta e má informação é possível esclarecer as diversas formas pelas quais a informação pode se mascarar e servir aos propósitos nocivos da infodemia: sejam eles o de falsear ou o de causar dano. Os apontamentos realizados refletem uma realidade problemática, que se configura em função da desordem da informação e coloca em risco as democracias que ainda não estão consolidadas. Quanto mais informações falsas, maior também é o esvaziamento dos sentidos informativos, assim como também o controle social, operado a partir das dimensões tecnopolíticas da informação, torna-se mais viável nestas condições.

Deste modo, a partir de todo o exposto nestas reflexões críticas, considera-se que toda essa gama de configurações sociais, somadas ao longo do tempo, caracterizadas pelo caos informacional e 
por processos comunicacionais complexos, em meio a infodemia das desinformações, que estes são elementos suficientes para caracterizar o contexto sociocomunicacional, deste início do século XXI, como próprio da sociedade da desinformação.

\section{Referências}

Almeida, M. A. (2009). A produção social do conhecimento na Sociedade da Informação. Informação \& Sociedade, 19(1), 11-18.

Araújo, C. A. Á. (2009). Teoria crítica da informação no Brasil: a contribuição de Armand Mattelart. RECIIS - R. Eletr. de Com. Inf. Inov. Saúde, 3(3), 112-119. https://www.arca.fiocruz.br/bitstream/icict/17481/2/11.pdf

Bennett, W. L., \& Livingston, S. (2018). The disinformation order: Disruptive communication and the decline of democratic institutions. European journal of communication, 33(2), 122-139.

Braudel, F. (1965). História e Ciências Sociais: a longa duração. Revista de História, 30 (62), 261. http://www.revistas.usp.br/revhistoria/article/view/123422 Berger, G. (2019). Prefácio. In Ireton, C., \& Posetti, J. (Eds.), Jornalismo, Fake News \& Desinformação: Manual para Educação e Treinamento em Jornalismo (pp 7-14). Organização das Nações Unidas Para A Educação, a Ciência e a Cultura - Unesco. https://unesdoc.unesco.org/ark:/48223/pfoooo368647

Berger, C. \& Schwaab, R. (2014). Escola Latino-americana de Comunicação (verbete). In Citelli, A., Berger, C., Baccega, M. A., Lopes, M. I. V., \& França, V. V. (Org.), Dicionário de Comunicação: escolas, teorias e autores, (pp.200-209). Contexto.

Canavilhas, J., Colussi, J., \& Moura, Z.-B. (2019). “Desinformación en las elecciones presidenciales 2018 en Brasil: un análisis de los grupos familiares en WhatsApp". El profesional de la información, 28(5), 1-9. https://doi. org/10.3145/epi.2019.sep.03

Castells, M. (1999). A sociedade em rede. Paz e Terra.

Henriques, C.M.P. (2018). A dupla epidemia: febre amarela e desinformação. RECIIS - R. Eletr. de Com. Inf. Inov. Saúde, 12(1), 9-13. https://doi.org/10.29397/ reciis.v12i1.1513

Faris, R., Roberts, H., Etling, B., Bourassa, N., Zuckerman, E., \& Benkler, Y. (2017). Partisanship, propaganda, and disinformation: Online media and the 2016 US presidential election. Berkman Klein Center for Internet \& Society Research Paper. https://dash.harvard.edu/handle/1/33759251 
Fernandes, C. M., \& Montuori C. (2020). A rede de desinformação e a saúde em risco: uma análise das fake news contidas em 'As 10 razões pelas quais você não deve vacinar seu filho'. RECIIS - R. Eletr. de Com. Inf. Inov. Saúde, 14(2), 444-46o. https://doi.org/10.29397/reciis.v14i2.1975

Ferrara, E. (2017). Disinformation and social bot operations in the run up to the 2017 French presidential election. First Monday, 22(8). doi: https://doi. org/10.5210/fm.v22i8.8005

Figueira, J., \& Santos, S. (Eds.). (2019). As fake news e a nova ordem (des) informativa na era da pós-verdade: Manipulação, Polarização, Filter Bubbles. Imprensa da Universidade de Coimbra.

Fuentes Navarro, R., \& Lopes, M. I. V. (2001). Comunicación: campo y objeto de estudio. Perspectivas reflexivas latinoamericanas. Iteso -Universidad de Guadalajara.

InfoMoney. Este gráfico mostra as 100 marcas mais valiosas do mundo em 2020. [S.l: s.n.]. https://www.infomoney.com.br/consumo/este-grafico-mostra-as100-marcas-mais-valiosas-do-mundo-em-2020/

Ireton, C., \& Posetti, J. (2019). Jornalismo, Fake News \& Desinformação: Manual para Educação e Treinamento em Jornalismo. Organização das Nações Unidas Para A Educação, a Ciência e a Cultura - Unesco. https://unesdoc.unesco.org/ark:/48223/pfoooo368647

Kaplún, Mario. (2002). Una pedagogia de la comunicación - el comunicador popular. Editorial Caminos.

Maldonado, A. E. (2014). Perspectivas transmetodológicas na pesquisa de sujeitos comunicantes em processo de receptividade comunicativa. In Maldonado, A. E., (coord.), Panorama da investigação em comunicação no Brasil. Processos receptivos, cidadania, dimensão digital (pp. 17-41). Comunicación Social. Maldonado, A. E. (2011). Pesquisa em Comunicação: trilhas históricas, contextualização, pesquisa empírica e pesquisa teórica. In: Maldonado, A. E., (org.), Metodologias de pesquisa em comunicação (pp. 277-303). Sulina.

Mattelart, A., \& Mattelart, M. (1999). História das teorias da comunicação. Loyola. Mattelart, A. (2002). História da sociedade da informação. Loyola.

Mattelart, A. (2008). Un mundo vigilado. Paidós.

Mattelart, A., \& Neveu, É. (2004). Introdução aos estudos culturais. Parabola.

Mattelart, A., \& Mattelart, M. (2004). Pensar as mídias. Loyola.

Mattelart, A., \& Mattelart, M. (1989). O carnaval das imagens: a ficção na TV. Brasiliense.

Mattelart, A. \& Vitalis, A. (2015). De Orwell al cibercontrol. Gedisa. 
NIC.BR. (2020). Relatório Internet, Desinformação e Democracia. https://cgi.br/ publicacao/relatorio-internet-desinformacao-e-democracia/

Pesquisa sobre o uso das tecnologias de informação e comunicação nos domicílios brasileiros: TIC Domicílios 2019 [livro eletrônico] = Survey on the use of information and communication technologies in Brazilian households : ICT Households 2019 / [editor] Núcleo de Informação e Coordenação do Ponto BR. -- 1. ed. -- São Paulo : Comitê Gestor da Internet no Brasil, 2020. ISBN 978-65-86949-22-3 [Disponível em: https://cetic.br/media/docs/publicacoes/2/20201123121817/tic_dom_2019_livro_eletronico.pdf ]

Sacramento, I., \& Paiva, R. (2020). Fake news, WhatsApp e a vacinação contra febre amarela no Brasil. MATRIZes, 14(1), 79-106. https://doi.org/10.11606/ issn.1982-8160.v14i1p79-106

Shannon, C. E., \& Weaver, W. (1949). The mathematical theory of communication. University of Illinois.

Sousa Jr., J.H., Raasch, M., Soares, J. C. \& Ribeiro, L. V. H. A. S. (2020). Da desinformação ao caos: uma análise das fake news frente à pandemia do coronavírus (covid-19) no Brasil. Cadernos de Prospecção, 13(2), 331-346. http:// dx.doi.org/10.9771/cp.v13i2.COVID-19.35978

Unesco (1980). Voix multiples, un seul monde: rapport Mac Bride:[vers un nouvel ordre de l'information et de la communication plus juste et plus efficace]. Rapport de la Commission internationale d'étude des problèmes de la communication. http://www.elcorreo.eu.org/IMG/pdf/voix_multiples_un_ seul_monde._unesco._rapport_sean_macbride_1976-1980_-_complet.pdf Wardle, C., \& Derakhshan, H. (2017). Information disorder: Toward an interdisciplinary framework for research and policy making (Council of Europe Report DGI (2017) 09). Council of Europe. https://rm.coe.int/information-disorder-toward-an-interdisciplinary-framework-for-researc $/ 168076277 \mathrm{c}$

Wardle, C., \& Derakhshan, H. (2019). Reflexão sobre a "desordem da informação": formatos da informação incorreta, desinformação e má-informação. In Ireton, C., \& Posetti, J. (Eds.), Jornalismo, Fake News \& Desinformação: Manual para Educação e Treinamento em Jornalismo (pp 46-58). Organização das Nações Unidas Para A Educação, a Ciência e a Cultura - Unesco. https:// unesdoc.unesco.org/ark:/48223/pfoooo368647

Wiener, N. (1948). Cybernetics or control and communication in the animal and the machine. Technology Press. 